Obere Extremität 2021 · 16:85-93 https://doi.org/10.1007/s11678-020-00620-x Received: 15 October 2020

Accepted: 21 December 2020

Published online: 22 January 2021

(c) The Author(s) 2021

\author{
Markus Loew ${ }^{1} \cdot$ Marc Schnetzke $^{1,2}$ (D) - Sven Lichtenberg ${ }^{1}$ \\ ${ }^{1}$ Atos Clinic Heidelberg, German Joint Centre Heidelberg, Heidelberg, Germany \\ ${ }^{2}$ BG Trauma Center Ludwigshafen, Clinic for Trauma and Orthopaedic Surgery at the University of \\ Heidelberg, Ludwigshafen on the Rhine, Germany
}

\title{
Current treatment concepts of calcifying tendinitis of the shoulder
}

\section{A systematic review}

\section{Calcifying tendinitis (CT) is one of the most common clinical conditions in the shoulder area. The range of symptoms is very diverse, from asymptomatic coincidental findings to pronounced pain with functional pseudoparalysis. This article provides an overview of the different stages of calcifying tendinitis with a corresponding treatment recommendation based on current literature data.}

There are few scientifically proven facts about the etiology of calcifications that occur in the human musculoskeletal system, located almost exclusively in the area of the rotator cuff and in the supraspinatus tendon in particular. Conversely, various findings on their epidemiology and pathogenesis have been confirmed.

Bosworth (1941; [3]) found periarticular calcifications in a radiologic survey of 12,122 shoulders of company employees, with an incidence of $2.7 \%$. In this cohort, $35 \%$ of the initially asymptomatic subjects developed clinical symptoms within 3 years. In an epidemiological study of 1219 adults by Louwerens et al. [19], 7.8\% of asymptomatic subjects and $42.5 \%$ of patients with subacromial pain syndrome exhibited radiologic calcium deposits.

Calcifying tendinitis is a benign selflimiting condition, in which phases of relatively minor symptoms on loadbearing only can alternate with those characterized by agonizing resting pain. At the end of these cyclic symptoms, the calcium deposit resolves spontaneously during the course of an inflammatory and often highly painful process. The only appreciable complication in the spontaneous course of CT is a phase of adhesive capsulitis, which is always reversible.

The presentation is especially problematic in that the disease course and particularly the duration cannot be predicted individually. While many patients suffer from recurring symptoms, sometimes for years, in others there is spontaneous recovery after a single episode of pain.

Gärtner [10,11] classified calcifications from a prognostic perspective into three types in terms of their radiologic presentation ( $\bullet$ Table 1 ), where type I was intended to correspond to a calcium deposit in the quiescent stage, type III to calcification in the process of resorption, and type II to intermediate calcification (- Fig. 1).

However, because of its low inter- and intraobserver reliability, this classification is of only limited value for reliably predicting the spontaneous course [22].

Against this background, the indication for the various treatment measures is open to dispute in individual cases. In the vast majority of cases, treatment is conservative with physiotherapy, but in protracted chronic or particularly painful courses, physical procedures may also be considered in the form of extracorporeal shock wave therapy (ESWT) and, last of all, (semi)invasive therapeutic options involving ultrasound- or X-ray-guided lavage (needling) and endoscopic interventions.

\section{Methods}

This review presents selected current studies of the individual treatment procedures and attempts to derive a treatment algorithm from these. The analysis included all reviews of level of evidence I (LoE I= systematic reviews or metaanalyses of randomized controlled trials [RCT] of evidence strength $\mathrm{Ib}$ ) that could be found in the electronic databases Medline (via PubMed), Embase (via OVID), and the Cochrane Library, and all the studies recorded in their list of references of level of evidence LoE $\mathrm{Ib}$ and IIa $(\mathrm{LoE}$ Ib = RCTs; LoE IIa $=$ controlled trials without and with quasirandomization) were analyzed. In addition, individual older trials of lower evidence (LoE IIb = well-planned case-control studies) were included in the analysis, either because of their high case numbers or because of an original problem statement.

\section{Results}

\section{Spontaneous course}

Epidemiological studies of the spontaneous course of CT are rare. In his extensive survey, Bosworth [3] observed spontaneous resorption of the calcifications in $9.3 \%$ of cases within 3 years. In Gärtner's publication [11], the calcium shadow on 
Table 1 Radiologic classification of calcifications according to Gärtner [11]

\section{Classification}

Type I

Type II

Type III

\section{Characteristics}

Sharply outlined, homogeneous, dense

Mixed type

Vaguely outlined, inhomogeneous, transparent

\section{Stage}

Quiescent phase Intermediate phase Resorption phase
Table 2 Comparison of the results of arthroscopic interventions in calcifying tendinitis

\begin{tabular}{|c|c|c|c|c|c|c|c|}
\hline Authors & LoE & $N$ & $\begin{array}{l}\text { Surgical proce- } \\
\text { dure }\end{array}$ & $\begin{array}{l}\text { FU } \\
\text { (months) }\end{array}$ & CS & VAS & DASH \\
\hline Clement [5] & II & 80 & $C E+A S A D$ vs. $C E$ & 12 & 82.4 vs. 77.5 & 1.6 vs. 2.5 & 14.5 vs. 14.0 \\
\hline Hofstee [13] & III & 40 & $C E+A S A D$ vs. $C E$ & 36 & - & 4.3 vs. 4.2 & 3.2 vs. 3.1 \\
\hline Marder [21] & III & 50 & $C E+A S A D$ vs. $C E$ & 60 & - & 11.1 vs. 6.3 & - \\
\hline
\end{tabular}

the radiologic image disappeared within 3 years in $33 \%$ of type I and in $71 \%$ of type II calcifications. In a prospective therapeutic study [12] of ESWT, 48 patients received placebo treatment only as a control group and were monitored over 12 months. Spontaneous resorption of the calcium deposit occurred in $11 \%$ of cases within 6 months and in 25\% after 12 months, and there was a substantial freedom from symptoms of the same scale.

The only relevant complication in the spontaneous course of CT is secondary shoulder stiffness, the incidence of which is not known and which is difficult to differentiate from primary adhesive capsulitis (frozen shoulder).

Osteolytic lesions in the area of the greater tubercle of the humerus or transmural lesions of the rotator cuff are very rare complications.

\section{Drugs and physiotherapy}

Conservative therapy attempts on the one hand to suppress the inflammatory pain symptomatically by means of systemic anti-inflammatory drugs and subacromial steroid injections, and on the other hand to stimulate the blood supply to the tendons by means of local pressure point massages and electrotherapy, and to counteract adhesive capsulitis by manual therapy. The efficacy of standardized conservative treatment was evaluated in a prospective cohort study [22] in $420 \mathrm{pa}-$ tients. In $73 \%$ of cases there was an improvement in symptoms, while $27 \%$ underwent endoscopic surgery following treatment failure. Patients with type III calcification in particular responded well to conservative treatment, whereas type I calcium deposits tended to cause further symptoms. Dependence of treatment outcome on the location of calcifications in the subacromial space was also described. However, there was no radiologic follow-up of treatment responders or nonresponders.

\section{Extracorporeal shock wave therapy}

\section{Focused ESWT}

Extracorporeal shock wave therapy (ESWT) was evaluated and introduced in the 1990s as a method of noninvasive treatment of CT [18]. It involves the generation of shock waves by means of piezoelectric, electromagnetic, or electrohydraulic sources, the energy of which, when focused at one point, causes mechanical disintegration of the calcium deposit and, as a result, is intended to convert the deposit from the quiescent to the resorption phase. According to the level of energy in the focus, lowenergy ESWT $\left(<0.06 \mathrm{~mJ} / \mathrm{mm}^{2}\right)$ is distinguished from high-energy ESWT $\left(<0.28 \mathrm{~mJ} / \mathrm{mm}^{2}\right)$. The precondition for these forms of ESWT is a positioning device in the apparatuses used that allows the shock waves to be focused on the calcium deposit. In a few cases, highenergy ESWT has been executed under general anesthesia or intravenous pain medication.
Gerdesmeyer et al. [12] conducted the first multicenter prospectively randomized controlled trial in which the effects of focused high-energy ESWT were compared with those of low-energy ESWT and a placebo group. A total of $147 \mathrm{pa}$ tients were observed over 12 months. In both ESWT groups there was a significant improvement in symptoms in the followups after 6 and 12 months. Complete disappearance of the calcium deposits was observed on the radiologic image in $86 \%$ after the high-energy treatment, in $37 \%$ after the low-energy treatment, and in $25 \%$ after the placebo treatment.

A further prospectively randomized trial [15] compared 33 patients with highenergy ESWT to 13 patients in a placebo group. Clinically, ESWT resulted in good and excellent results after 1 year in $88 \%$ of cases, compared with $0 \%$ in the control group. Radiologic changes in the calcium deposits occurred in $56 \%$ of the ESWT group compared to $15 \%$ in the placebo group.

To compare the efficacy of low- versus high-energy ESWT, Verstraelen et al. [32] undertook a meta-analysis that included five randomized trials $[1,12,18$, 24, 26]. All studies demonstrated the superiority of high-energy ESWT in terms of the clinical and functional course of $\mathrm{CT}$ as measured by the Constant score. In the studies that analyzed the radiologic changes $[1,12,18]$, resorption of the calcium deposits was described within 3 months in $25 \%$ of cases after highenergy ESWT and in 10\% of cases after low-energy ESWT. Statistical analysis revealed a significantly higher chance of calcium resorption after high-energy ESWT (odds ratio 3.4; $p=0.009$ ). Further meta-analyses $[16,30]$ confirmed these results.

\section{Radial ESWT}

Not to be confused with focused ESWT, radial shock wave therapy (rESWT) involves the use of shock waves that are not bundled and are intended to exert circulation-enhancing and analgesic rather than mechanical effects on the connective tissue in enthesopathies.

Only one RCT of the radiological course [4] has been published on rESWT for CT of the shoulder. In 
Hier steht eine Anzeige.

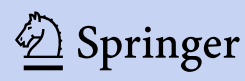


45 patients undergoing rESWT, complete resorption was described in $86.6 \%$ after 6 months and partial resorption in $13.4 \%$ (corresponding to a success rate of $100 \%$ in total), whereas, in comparison, only $8.8 \%$ in an untreated control group had partial resorption of the calcium deposits. However, these results were not reproduced in a more recent study [6]. In this case, calcium resorption was described in only one out of 14 subjects (7\%) over a short-term course of 6 weeks.

All other publications simply analyzed the pain response after rESWT in subacromial pain syndrome [9].

\section{Needling and lavage}

Needling describes puncture of the calcium deposits with a large-bore cannula, which was undertaken in the past under the guidance of an image converter and in the last few years has been predominantly ultrasound guided. In this process, the calcium deposits are simply opened or rinsed with normal saline solution. In many cases, a steroid preparation is then injected into the subacromial space.

In a meta-analysis [33], 254 studies on the topic of ultrasound-guided lavage were analyzed, but of these only 8 publications with a total of 617 subjects met the criteria for a study of LoE II. In five of the studies, the Constant score before and at least 6 months after the beginning of the study or treatment was examined as a criterion. An improvement was found in both groups, with statistical superiority of the lavage group over the control group. Five studies likewise investigated the frequency of calcium resorption on $\mathrm{X}$-ray. Also in terms of this criterion was a significant difference found in the lavage group (165/220 patients, $75 \%$ ) compared with the control group (76/184 patients, $41 \%)$. Complications were reported in $3.6 \%$ after lavage and in $2.4 \%$ of the control group, although the nature of the adverse effects was not described in further detail. Of subjects from the lavage group, $12 \%$ subsequently underwent surgery as opposed to $27 \%$ from the control group.

In an LoE IIa study, De Witte et al. [8] investigated the effect of lavage with a steroid injection versus injection alone. The clinical course in terms of the Con-

Obere Extremität 2021 · 16:85-93 https://doi.org/10.1007/s11678-020-00620-x

(c) The Author(s) 2021

\section{Loew $\cdot$ M. Schnetzke $\cdot$ S. Lichtenberg}

\section{Current treatment concepts of calcifying tendinitis of the shoulder. A systematic review}

\begin{abstract}
Calcifying tendinitis is a very common pathology in the shoulder region, which may be acute or chronic. The rotator cuff, particularly the supraspinatus tendon, is most frequently affected. The tendons of the rotator cuff undergo a natural cycle of destruction and regeneration. The development of calcifying tendinitis is caused by defective tendon repair. Typical is a chronic course with acute pain exacerbation, which leads to medical presentation. Treatment options range from
\end{abstract}

conservative therapy including rest, physical therapy, nonsteroidal anti-inflammatory drugs, and shock wave therapy, to surgical therapy with arthroscopic removal of the calcific focus. This article discusses the current stage-dependent therapeutic concepts and provides a treatment recommendation.

Keywords

Tendinopathy · Extracorporeal shockwave therapy · Tendons · Pain · Rotator cuff

\section{Aktuelle Behandlungskonzepte der Tendinosis calcarea der Schulter. Ein systematisches Review}

\section{Zusammenfassung}

Die Tendinosis calcarea stellt eine sehr häufige, akute oder chronische, pathologische Veränderung im Bereich der Schulter dar. Am häufigsten ist dabei die Rotatorenmanschette und hier insbesondere die Supraspinatussehne betroffen. Die Sehnen der Rotatorenmanschette unterliegen einem natürlichen Kreislauf von Sehnenabbau und -regeneration. Ursächlich für die Entstehung des Kalkherds ist eine fehlerhafte Sehnenreparatur. Typisch ist ein chronischer Verlauf mit akuter Schmerzexazerbation, welche zu einer ärztlichen Vorstellung führt. Die Therapiemöglichkeiten reichen von der konservativen Therapie, u.a. mit Schonung, physikalischer Therapie, nichtsteroidalen entzündungshemmenden Medikamenten und Stoßwellentherapie, bis hin zur operativen Therapie mit arthroskopischer Entfernung des Kalkherds. Im vorliegenden Beitrag werden stadienabhängig die aktuellen Therapiekonzepte diskutiert und eine Behandlungsempfehlung gegeben.

\section{Schlüsselwörter}

Tendinopathie - Extrakorporale Stoßwellentherapie - Sehnen · Schmerzen . Rotatorenmanschette stant score did not differ significantly between the two groups in the first 3 months. After 1 year, the CS in the combined group was 86 points as opposed to 73 points in the injection group $(p<0.005)$. After 1 year, complete resorption of the calcium deposits was seen in $13 / 23$ patients (56\%) after lavage plus steroid compared to $6 / 25$ patients $(24 \%)$ after injection alone.

\section{Lavage versus ESWT}

In a prospective RCT in 201 patients, DelCastillo et al. [7] compared the effects of lavage (with an additional steroid injection) to those of ESWT (without steroid). The criteria of pain on a visual analogue scale (VAS) and development in size of the calcium deposits were monitored by ultrasound and analyzed over a 12-month period after treatment. In both groups, a significant reduction in pain occurred over the course of time, with a positive correlation between improvement in VAS and reduction in size of the calcium deposits. No relevant adverse effects or complications were observed, apart from pain on ESWT and vasovagal reactions in $5 \%$ of cases during lavage. Freedom from pain was achieved at the endpoint in $89 \%$ after lavage and in $82 \%$ after ESWT $(p=0.13)$, and the calcium deposits were no longer visualizable on ultrasound in $87 \%$ after lavage and in 56\% after ESWT $(p<0.0001)$.

In a prospectively randomized trial, De Boer et al. [6] compared the effect of 


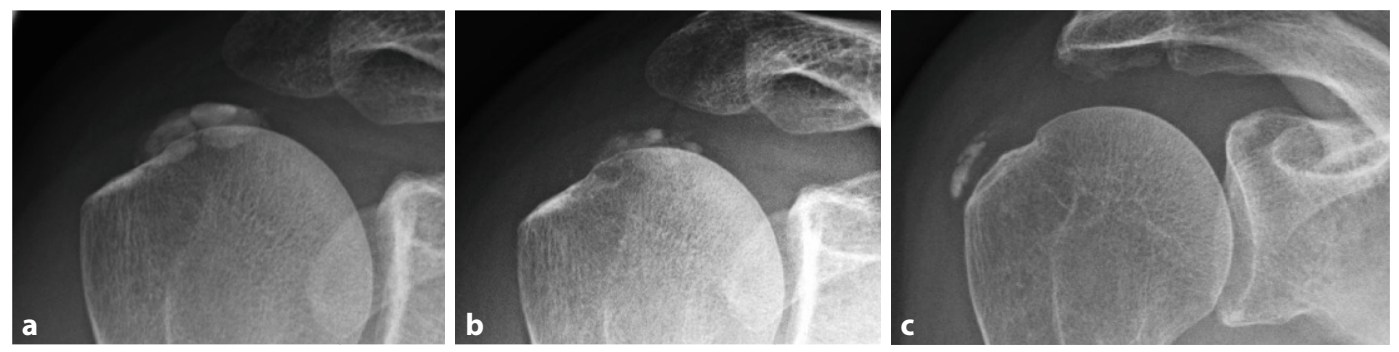

Fig. $1 \Delta$ Radiologic classification of calcifications according to Gärtner. a Type I: dual-segment, compact, homogeneous calcium deposit. b Type Il: same patient as a after extracorporeal shock wave therapy. Dispersed, multisegmented calcification, no longer smoothly outlined. c Type III: cloudy, inhomogeneous calcification with blurred outlines obviously in the stage of disintegration

rESWT with lavage (with an additional steroid injection) on the clinical and radiological course of CT in a very small cohort $(n=25)$ with a 12 -month followup. Five of the 14 subjects after rESWT $(36 \%)$ and one of the 11 subjects after lavage (10\%) discontinued the study because of treatment failure and underwent surgery. After 1 year, $40 \%$ in both groups were free from symptoms. In one of the remaining 9 patients, calcium resorption occurred after rESWT as opposed to in 5 of 10 patients after lavage.

\section{Surgical treatment options}

Because of the risk of complications associated with its invasive nature, a surgical intervention should be regarded as a last resort in the treatment of CT. Surgery includes three endoscopic procedures: calcium excision (CE), arthroscopic subacromial decompression (ASAD), and a combination of CE with ASAD. There is also discussion as to whether in the case of $\mathrm{CE}$, the incised tendon fascia should be closed or whether it should be left open.

A current literature search [31] analyzed all the articles listed in Medline, Embase, Cinahl, and Cochrane on this subject and out of 574 publications, found only 6 LoE II or III studies in which comparisons were undertaken between individual surgical procedures, but not a single study with an untreated control group. The subjective and functional success rate was between 73 and $80 \%$ with all procedures studied.

From a functional and clinical viewpoint, there was no difference in three studies between the procedures with
$\mathrm{CE}$ alone compared to CE plus ASAD (• Table 2). Verstraelen [31] concludes that there is no relationship between CT and subacromial impingement.

On the other hand, the authors Hofstee et al. [13] and Tilander et al. [29] reported no difference between ASAD alone and ASAD plus CE in their longterm studies. These observations appear to support a correlation between CT and impingement.

Maier et al. [20] and Rubenthaler et al. [27] found no difference in results between two groups in which $\mathrm{CE}$ and decompression were undertaken arthroscopically or open.

Porcellini et al. [23] analyzed the results after endoscopic CE with or without suture of the incised fascia in a retrospective study. After 2 years, significantly better clinical results were found in patients in whom the calcium had been completely removed compared to those with residual calcium deposits. At the same time, fascial suture does not yield any better results. No secondary tendon lesions were described on ultrasound follow-up. Nevertheless, the authors recommended closure of the fascia after CE. Balke et al. [2] did not share this recommendation following their retrospective analysis of 70 shoulders. However, they found a partial lesion of the supraspinatus tendon on ultrasound in $22 \%$ of cases at an average of 6 years (2-13 years) after the intervention. Shoulder function was significantly poorer on the operated side than on the contralateral side.

Ranaletta et al. [25] regularly performed a side-to-side suture or a transosseous suture using the suture anchor repair technique in 30 patients after $\mathrm{CE}$, depending on the position and extent of the residual tendon defect. In $21 \mathrm{pa}-$ tients, MRI was performed a mean of 3 years postoperatively and revealed complete integrity of the tendons concerned in all cases.

A comparative analysis of complications was not performed in the literature search [31]. However, not a single patient in all the studies cited had to undergo revision because of a complication.

The frequency of transient secondary shoulder stiffness following various arthroscopic interventions is reported by Jacobs and de Beer [17] as $18 \%$. According to their retrospective analysis of 61 patients, this occurred in the early postoperative phase and did not affect the final outcome after a mean followup of 15 months.

\section{Discussion}

Although calcifying tendinitis of the shoulder is a self-limiting condition in which spontaneous calcium resorption and hence freedom from symptoms is to be expected in many cases over a period of 1 to 3 years, this perspective represents an unacceptable situation for the majority of sufferers, particularly because of the impossibility of predicting the individual course. For this reason, symptomatic conservative treatment should be considered in most cases and also an invasive intervention in selected patients in the event of a chronic course.

Surgical removal of calcium deposits is generally viewed as the "treatment of last choice" because it is said to be associated with high costs, the highest risk of complications, and the longest rehabili- 


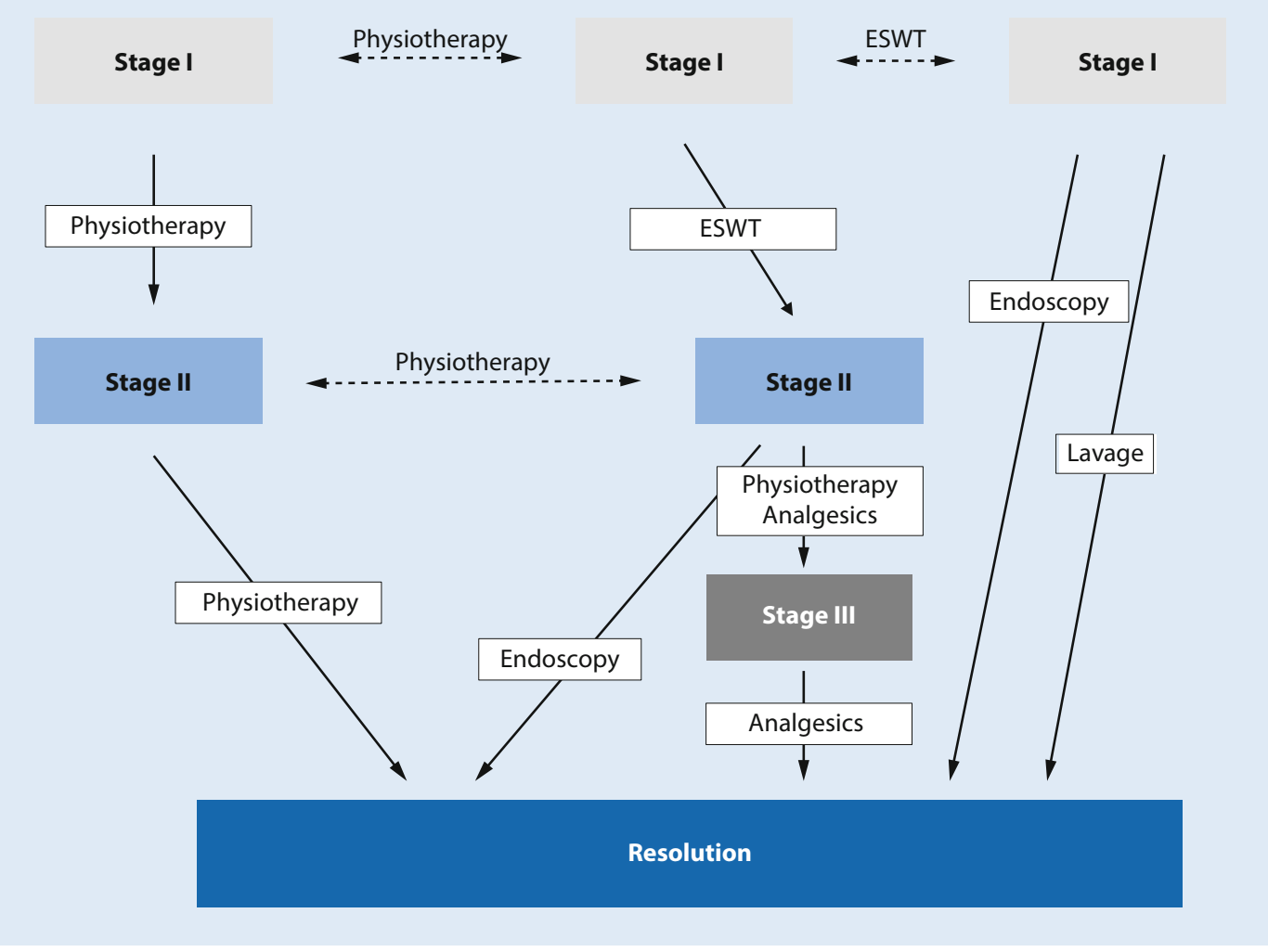

Fig. $2<$ Treatment algorithm in calcifying tendinitis of the shoulder. ESWT extracorporeal shock wave therapy

tation time. However, there is not yet any scientific evidence for this assumption.

In a systematic literature review, Louwerens etal. [19] analyzed 20 prospective, controlled, and (quasi)randomized trials of the efficacy of noninvasive treatment procedures (high-energy ESWT, rESWT, lavage, subacromial steroid injection, transcutaneous nerve stimulation [TENS], laser, and ultrasound therapy) with type I and II calcium deposits with a minimum follow-up of 3 months. The authors came to the conclusion that high-energy focused ESWT is the most exhaustively studied treatment procedure, which can be regarded as safe and effective in the short and medium term. Ultrasound-guided lavage has proved an equally safe procedure to subacromial steroid injection, but is no more effective.

The indication for the individually recommended therapeutic measures must be geared to the expected spontaneous course. In this respect, even considering the limited reliability of Gärtners classification, the radiologic image provides an important aid.
Calcifications of radiologic type III are highly likely to be in a stage of resorption and there is no indication for invasive therapeutic measures. Because of the associated pain, ESWT is not feasible in this phase.

Decision-making is more difficult in radiologic types I and II. In the case of these images, spontaneous resorption is to be expected in between 9 and 25\% of cases within 1 year $[3,11,12]$. Conservative treatment in these stages can result in an improvement in symptoms in $70 \%$ of cases [22].

High-energy ESWT results in spontaneous resorption of type I calcifications within a year in $86 \%$ of cases [12]; the results following low-energy ESWT and radial ESWT are contradictory $[12,14$, $16,18,19,24,26,28,30,32]$. When high-energy ESWT is performed under local anesthesia, it has strictly speaking to be called a semi-invasive procedure.

Ultrasound-guided lavage with or without steroid injection results in an improvement in symptoms within 3 months in about $80 \%$ of cases, but this only persists if there is resorption of the calcium deposit.
Endoscopic removal of calcium deposits with or without ASAD resulted in freedom from symptoms in about $80 \%$ of cases within 6-26 weeks. The result depends on the complete elimination or resorption of the calcium deposit at the time of the follow-up examination.

Most authors recommend additional ASAD only in cases of a radiologically detectable acromial spur or traces of wear at the front of the acromion on arthroscopy.

For the authors, the findings summarized in this literature analysis yield the treatment algorithm depicted in • Fig. 2 . At the same time, treatment must be geared to the individual presentation, the functional restrictions, the radiologic calcification type and, not least, to the individual needs of patients, who must be informed of all treatment options.

Of course, any incidentally detected asymptomatic calcifications have not to be treated at all. On first diagnosis of a previously untreated CT with tolerable symptoms and of radiologic type I, physiotherapy is initiated with the aim of stimulating vascularization of the tendon and hence improving the conditions for resorption of the calcium deposit. Com- 
Hier steht eine Anzeige.

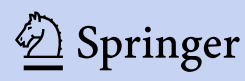


plementary focused ESWT can result in disintegration of the calcium deposit in about half of cases. If this is unsuccessful, needling with lavage should be considered as a semi-invasive treatment measure. As the spectrum of complications is comparable to that of endoscopic CE, in this situation the authors prefer the latter procedure because of the greater prospects of success.

In the case of a primary diagnosis in the intermediate stage with radiologic type II, analgesia with NSAIDs should be undertaken in addition to physiotherapy, if necessary in combination with subacromial injection of a steroid preparation mixed with a local anesthetic. In the absence of success, endoscopic CE is performed.

On first diagnosis in radiologic stage III, which in many cases is accompanied by violent pain, invasive measures are not indicated. In this case, consistent pain therapy with subacromial injection and potent analgesics, where necessary opioids, is recommended, since a short-term spontaneous recovery may be expected.

\section{Practical conclusion}

- Calcifying tendinitis (CT) of the shoulder is a self-limiting condition in which spontaneous resolution can be expected in many cases over a period of 1-3 years.

- Due to considerable pain and the impossibility of predicting the individual course, symptomatic conservative treatment should be considered in most cases as well as an invasive intervention in selected patients with chronic CT.

- The indication for individually recommended therapeutic measures must be geared to the expected spontaneous course. Noninvasive treatment procedures include extracorporeal shock wave therapy, lavage, subacromial steroid injection, transcutaneous nerve stimulation, laser, and ultrasound therapy.

- Surgical removal of calcium deposits is generally viewed as the "treatment of last choice."

\section{Corresponding address}

\section{Marc Schnetzke, MD}

Atos Clinic Heidelberg, German Joint Centre Heidelberg

Bismarckstraße 9-15, 69115 Heidelberg,

Germany

marc.schnetzke@atos.de

\section{Compliance with ethical guidelines}

Conflict of interest. M. Loew received royalties from Wright/Tornier Inc., not related to the subject of this work. S. Lichtenberg is paid consultant from Arthrex und Exactech and received Royalties von Arthrex, not related to the subject of this work. No company had any input into the review, data analysis, or manuscript preparation. The other authors, their immediate families, and any research foundations with which they are affiliated have not received any financial payments or other benefits from any commercial entity related to the subject of this article. M. Schnetzke declares that he has no competing interests.

For this article no studies with human participants or animals were performed by any of the authors. All studies performed were in accordance with the ethical standards indicated in each case.

Open Access. This article is licensed under a Creative Commons Attribution 4.0 International License, which permits use, sharing, adaptation, distribution and reproduction in any medium or format, as long as you give appropriate credit to the original author(s) and the source, provide a link to the Creative Commons licence, and indicate if changes were made. The images or other third party material in this article are included in the article's Creative Commons licence, unless indicated otherwise in a credit line to the material. If material is not included in the article's Creative Commons licence and your intended use is not permitted by statutory regulation or exceeds the permitted use, you will need to obtain permission directly from the copyright holder. To view a copy of this licence, visit http://creativecommons.org/licenses/by/4.0/.

\section{References}

\section{Cited Literatur}

1. Albert JD, Meadeb J, Guggenbuhl P, Marin F, Benkalfate T, Thomazeau H, Chale's G (2007) High-energy extracorporeal shockwave therapy for calcifying tendinitis of the rotator cuff: a randomised trial. JBone Joint Surg Br 89:335-341

2. Balke M, Bielefeld R, Schmidt C, Dedy N, Liem D (2012) Calcifying tendinitis of the shoulder: midterm results after arthroscopic treatment. Am J Sports Med 40(3):657-661

3. Bosworth B (1941) Calcium deposits in the shoulder and subacromial bursitis: a survey of 12122 shoulders. JAMA 116:2477-2488

4. Cacchio A, Paoloni M, Barile A, Don R, de Paulis F, Calvisi V, Ranavolo A, Frascarelli M, Santilli V Spacca G (2006) Effectiveness of radial shockwave therapy for calcific tendinitis of the shoulder: single-blind, randomized clinical study. Phys Ther 86:672-682

5. Clement N, Watts A, Phillips C, McBirnie J (2015) Short-term outcome after arthroscopic bursectomy debridement of rotator cuff calcific tendonopathy with and without subacromial decompression: a prospective randomized controlled trial. Arthroscopy 31:1680-1687

6. De Boer F, Mocking F, Nelissen E, Van Kampen P, Huijsmans $P$ (2017) Ultrasound guided needling vs radial shockwave therapy in calcific tendinitis of the shoulder: a prospective randomized trial. JOrthop 14:466-469

7. Del Castillo-Gonzalez F, Ramos-Alvarez J, Rodriguez-Fabian G et al (2016) Extracorporeal shockwaves versus ultrasound-guided percutaneous lavage for the treatment of rotator cuff calcific tendinopathy: a randomized controlled trial. Eur JPhys Rehabil Med 52:145-151

8. Bas de Witte P, Selten JW, Navas A, Nagels J, VisserC, Nelissen R, Reijnierse M (2013) Calcific tendinitis of the rotator cuff: a randomized controlled trial of ultrasound-guided needling and lavage versus subacromial corticosteroids. Am J Sports Med 41:1665-1673

9. Engebretsen K, GrotleM,Bautz-HolterE, Ekeberg O, Juel N, Brox J (2011) Supervised exercises compared with radial extracorporeal shock-wave therapy for subacromial shoulder pain: 1-year results of a single-blind randomized controlled trial. Phys Ther 91:37-47

10. Gaertner J (1993) Tendinosis calcarea Behandlungsergebnisse mit dem Needling. Z Orthop Unfall 131:461-469

11. Gaertner J, Simons B (1990) Analysis of calcific deposits in calcifying tendinitis. Clin Orthop Relat Res 254:111-120

12. Gerdesmeyer L, Wagenpfeil F, Haake M, Maier M, Loew M, Wörtler K, Lampe R, Seil R, Handle G, Gassel S, Rompe JD (2003) Extracorporal shock wave therapy for treatment of chronic calcifying tendonitis of the rotator cuff-a randomized controlled trial. JAMA 290:2573-2580

13. Hofstee DJ, Gosens T, Bonnet M, De Waal Malefijt J (2007) Calcifications in the cuff: take it or leave it? Br J Sports Med 41:832-835

14. Huisstede BM, Gebremariam L, van der Sande R, Hay EM, Koes BW (2001) Evidence for effectiveness of extracorporal shock-wave therapy (ESWT) to treat calcific and non-calcific rotator cuff tendinosis: a systematic review. Man Ther 16:419-433

15. Hsu C, Tseng K, Fong Y, Hsu H, Jim Y (2008) Extracorporeal shock wave therapy for calcifying tendinitis of the shoulder. J Shoulder Elbow Surg 17:55-59

16. loppolo F, Tattoli M, Di Sante L, Venditto T, Tognolo L, Delicata M, Rizzo G, Di Tanna G, Santilli V (2013) Clinical improvement and resorption of calcifications in calcific tendinitis of the shoulder after shock wave therapy at 6 months' follow-up: a systematic review and meta-analysis. Arch Phys Med Rehabil 94:1699-1706

17. Jacobs R, Debeer P (2006) Calcifying tendinitis of the rotator cuff: functional outcome after arthroscopic treatment. Acta Orthop Belg 72(3):276-281

18. Loew M, Daecke W, Kusnierczak D, Rahmanzadeh M, Ewerbeck V (1999) Shock-wave therapy is effective for chronic calcifying tendinitis of the shoulder. JBone Joint Surg Br 81:863-867

19. Louwerens J, Sierevelt I, van Noort A, van den Bekerom M (2014) Evidence for minimally invasive therapies in the management of chronic calcific 
tendinopathy of the rotator cuff: a systematic review and meta-analysis. J Shoulder Elbow Surg 23:1240-1249

20. Maier M, Maier-Bosse T, Eckermann M, MaierBosse E, Schulz CU, Steinborn M, Kleen M, Stäbler A (2003) Die röntgenmorphologische Gestalt symptomatischer Verkalkungen bei Patienten mit Tendinosis calcarea der Schulter. Bestimmung der Intra- und Interobserver-Variabilitäten der Gärtner-Klassifikation. Unfallchirurg 106:185-189

21. Marder RA, Heiden EA, Kim S (2011) Calcific tendonitis of the shoulder: is subacromial decompression in combination with removal of the calcific deposit beneficial? J Shoulder Elbow Surg 20:955-960

22. Ogon P, Suedkamp N, Jaeger M, Izadpanah K, Koestler W, Maier D (2009) Prognostic factors in nonoperative therapy for chronic symptomatic calcific tendinitis of the shoulder. Arthritis Rheum 60(10):2978-2984

23. Porcellini G, Paladini P, Campi F, Paganelli M (2004) Arthroscopic treatment of calcifying tendinitis of the shoulder: clinical and ultrasonographic followup findings at two to five years. J Shoulder Elbow Surg 13:503-508

24. Pleiner J, Crevenna R, Langenberger $H$, Keilani $M$, Nuhr $M$, Kainberger $F$, Wolzt $M$, Wiesinger $G$, Quittan M (2004) Extracorporeal shockwave treatment is effective in calcific tendonitis of the shoulder. A randomized controlled trial. Wien Klin Wochenschr 31:536-541

25. Ranalletta M, Rossi LA, Bongiovanni SL, Tanoira I, Piuzzi N, Maignon G (2015) Arthroscopic removal and rotator cuff repair without acromioplasty for the treatment of symptomatic calcifying tendinitis of the supraspinatus tendon. Orthop J Sports Med 3:1-5

26. Rompe J, Burger R, Hopf C, Eysel P (1998) Shoulder function after extracorporal shock wave therapy for calcific tendinitis. J Shoulder Elbow Surg 7:505-509

27. Rubenthaler F, Ludwig J, Wiese M, Wittenberg RH (2003) Prospective randomized surgical treatments for calcifying tendinopathy. Clin Orthop Relat Res 410:278-284

28. Surace S, Deitch J, Johnston R, Buchbinder R (2020) Shock wave therapy for rotator cuff disease with or without calcification. Cochrane Database Syst Rev 3:CD8962

29. Tillander B, Norlin R (1998) Change of calcifications after arthroscopic subacromial decompression. JShoulderElbow Surg 7:213-217

30. Vavken P, Holinka J, Rompe JD, Dorotka R (2009) Focused extracorporeal shock wave therapy in calcifying tendinitis of the shoulder: a metaanalysis. Sports Health 1:137-144

31. Verstraelen F, Fievez E, Janssen L, Morrenhof W (2017) Surgery for calcifying tendinitis of the shoulder: a systematic review. World J Orthop 8:424-430

32. Verstraelen F, in den Kleef N, Jansen L, Morrenhof J (2014) High-energy versus low-energy extracorporeal shock wave therapy for calcifying tendinitis of the shoulder: which is superior? A meta-analysis. Clin Orthop Relat Res 472:2816-2825

33. Zhang T, Duan Y, Chen J, Chen X (2019) Efficacy of ultrasound-guided percutaneous lavage for rotator cuff calcific tendinopathy - a systematic review and meta-analysis. Medicine 98:21

\section{Further Reading}

34. Castillo-Gonzalez F, Ramos-Alvarez J, RodriguezFabian $G$ et al (2014) Treatment of the calcific tendinopathy of the rotator cuff by ultrasoundguided percutaneous needle lavage - a two years prospective study. Muscles Ligaments Tendons J 4:220-255

35. Kim Y, Lee H, Kim Y et al (2014) Which method is more effective in treatment of calcific tendinitis in the shoulder? Prospective randomized comparison between ultrasound-guided needling and extracorporeal shock wave therapy. JShoulder Elbow Surg 23:1640-1646

36. Louwerens J, Sierevel I, van Hove $R$, van den Bekerom M, van Noort A (2015) Prevalence of calcific deposits within the rotator cuff tendons in adults with and without subacromial pain syndrome: clinical and radiologic analysis of 1219 patients. J Shoulder Elbow Surg 24:1588-1593

37. Maier M, Krauter T, Pellengahr C, Schulz CU, Trouillier H, Anetzberger H, Refior H (2002) Open surgical procedures in calcifying tendinitis of the shoulder-concomitant pathologiesaffect clinical outcome. ZOrthop Ihre Grenzgeb 140:656-661

38. Merolla G, Bhat MG, Paladini P, Porcellini G (2015) Complications of calcific tendinitis of the shoulder: a concise review. J Orthop Traumatol 16:175-183

39. Merolla G, Singh S, Paladini P, Porcellini G (2016) Calcific tendinitis of the rotator cuff: state of the art in diagnosis and treatment. J Orthop Traumatol 17(1):7-14

40. Rebuzzi E, Coletti N, Schiavetti S, Giusto F (2008) Arthroscopy surgery versus shock wave therapy for chronic calcifying tendinitis of the shoulder. JOrthop Traumatol 9(4):179-185

41. Sconfienza L, Randelli F, Sdao S et al (2014) Septic bursitis after ultrasound-guided percutaneous treatment of rotator cuff calcific tendinopathy. PMR 6:746-748

42. Umamahesvarana $B$, Sambandamb $S$ Mounasamyc V, Gokulakrishnana P, Ashrafa M (2018) Calcifying tendinitis of shoulder: a concise review. JOrthop 15:776-782 